\title{
Software Teaching in Pump Performance Experiment
}

\author{
Bin YANG \\ School of Automotive and Transportation, Tianjin University of Technology and Education, Tianjin, China
}

\begin{abstract}
During performing function experiment of testing pump, there are some inevitable difficulties that oil may be blown out because the students do not leave deep impression to correlation process and often reverse order of experimental step and experimental process may be terminated because a teacher can't guild eight students at the same time. A three-dimensional teaching software was established according to performance experiment of testing pump by correlation platform software. It can help the students to prepare lessons of testing pump function before class. Furthermore, it can help the students to remember the key point of function experiment of pump and to easily understand the general order of function experiment of pump. Classroom instruction and practice instructions can be combined by the three-dimensional teaching software. It provides a new method for teaching innovation in classroom.
\end{abstract}

KEYWORD: a three-dimension teaching software; pump; teaching innovation in classroom

\section{THE METHOD AND EXISTING DIFFICULTIES OF TRADITIONAL TEACHING AND STUDYING}

\subsection{The method of traditional teaching and studying}

(1)experimental goals:

The main function of pump should be understood.

The testing method of the minor capacity pump should be held.

(2)The experimental condition

Equipments: TP500 FESTO hydraulic equipments for training

Parts: hydraulic equipments, distributing plate with pressure gage, relief valve, unloading valve, measuring cup and the flexible pressure tube with rapid exchange device

Tools: stopwatch

(3)The principle and process of the experiment

(4) The experimental procedure and method

The hydraulic circuit was shown as Fig.1.

Firstly, the whole hydraulic circuit was connected. All control valves were set as the maximal position.

Secondly, the throttle valve was shut off. The relief valve was adjusted to ensure 50bar pressure in the hydraulic circuit.

At last, the theoretical flow was tested by adjusting the throttle valve when the pressure value was Obar in the hydraulic circuit.
The actual flow was tested by adjusting the throttle valve when the pressure value was selected as the different value acted upon the demand of teacher.

(5)The matters needing attention

The oil inlet and the oil return port of the throttle valve and the relief valvemust not connect reverse side during connecting the hydraulic circuit.

The flexible pressure tube must be connected firmly. Or the oil maybe be blowouteven hurting somebody.

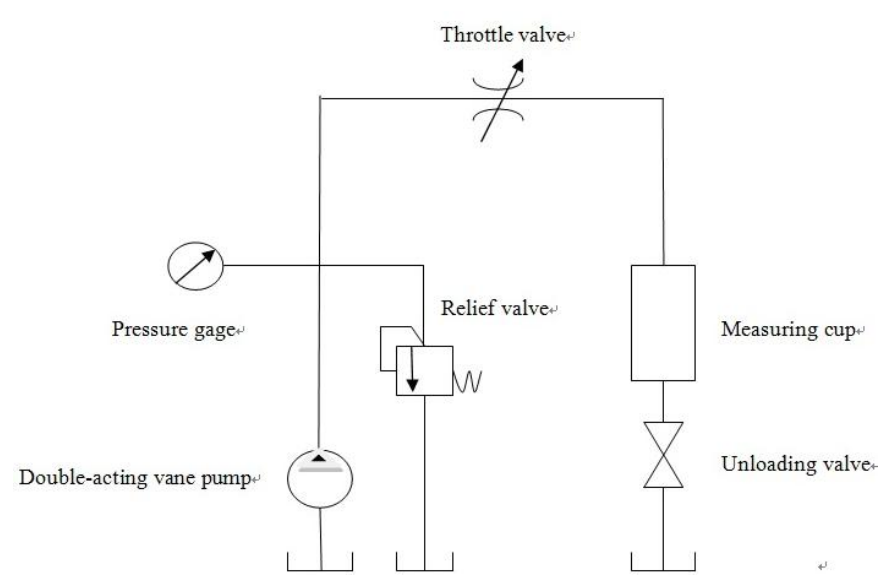

Fig.1 The circuit figure of hydraulic system

\subsection{The existing difficulties}

During experimental course, the correlation principle 
has been taught in classroom and the hydraulic circuit could be connected acting upon Fig.1. The experimental procedure and method could be followed as the above.

The points need to be thought as follows:

If the flexible pressure tube did not be connected firmly, the oil maybe be blowout even hurting somebody. Even if the dangerous has been told and warned before experiment, but since this was the first time to carry out the experiment for the students. The students often forget or neglect the dangerous. Thus, if the pump was started before the hydraulic circuit has been inspected by the teacher, it must be at the risk of serious consequence.

Although the oil inlet and oil return port of the throttle valve and the relief valve has been told, but it still existed many problems during the practice process because the students recognized the hydraulic components for the first time. Furthermore, the double-acting vane pump, the throttle valve and the relief valve were connected with the pressure gage. The oil inlet and the oil return port of the pressure gage don't exist obvious difference. During the experiment course, because the whole experiment was guided by only one teacher and the students were divided into 8 groups, so the experiment course might be terminated and reduce studying rate of students and working rate of teacher if too much problems would be occurred.

\section{ESTABLISHING A TEACHING THREE-} DIMENSION SOFTWARE OF HYDRAULIC PUMP PERFORMANCE TEST AND ITS MAIN FEATURES

\subsection{Establishing a teaching three-dimension software of hydraulic pump performance test}

Pro-E(Pro/Engineer) is a sort of three-dimension software combined three sorts of CAD,CAM and CAE. It is currently the most frequently used and the most widely used simulation software by technology workers at home and abroad. Meanwhile, the software also provides a comprehensive, integrated, cohesive product development environment. It can be used as a platform for secondary development. The teaching three-dimension software of hydraulic pump performance test was established by Pro-E (Pro / Engineer) software as a platform for secondary development.

The hydraulic components model of teaching three-dimension software of hydraulic pump performance test should be close to the actual characteristics of actual hydraulic components, in particular, the various ports of hydraulic components must coincide with the actual hydraulic components ports to meet the needs of the actual experiment. Control opening degree knobs of the throttle valve and the relief valve might also be made in accordance with reality acting upon clockwise or counterclockwise direction. In the three-dimensional educational software, two locations close stalls were made used to achieve a connection between the flexible pressure tube and the hydraulic components. The first position indicates the circumstances that the flexible pressure tube is not connected firmly, The second position indicates the circumstances that the flexible pressure tube is connected firmly, After the hydraulic system started, if the flexible pressure tube did not connect, it was set to blue, indicating the serious consequences of this kind of situation would be produced.

\subsection{Interactive can be achieved and teaching effectiveness can be improved}

(1) In the classroom teaching process, general hydraulic graphics can be converted into real physical graphics to explain.

In actual classroom teaching process, the related graphics in books are schematics and hydraulic system graphics. It is easy to analyze and explain the theory. But it is not easy to link the graphics with the actual hydraulic components for students, which resulted in disjointed between theoretical teaching with practical operation of the hydraulic system. The three-dimensional graphics of hydraulic components was adopted to teach. It can improve students' intuitive understanding of the actual hydraulic components, and help to improve the ability of students to integrate theory with practice. It was shown in Fig. 2.

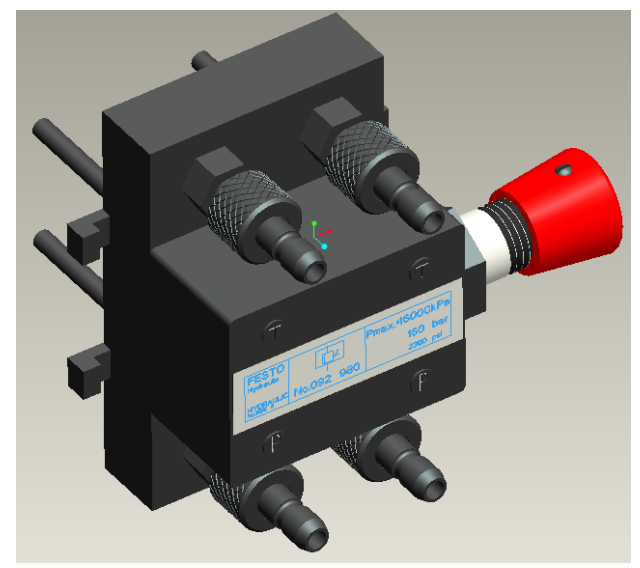

Fig.2 Relief valve

(2)It was used either as preparation of a hydraulic pump performance test or as physical simulation diagram of different valves body in the classroom teaching process.

The teaching three-dimension software of hydraulic pump performance test can use as preparation of a hydraulic pump performance test. It can help students remember the precautions during the experiment and learn about the external features and interface characteristics of hydraulic 
components. It can perform the experiment smoothly and effectively. The teaching threedimension software of hydraulic pump performance test can use as an auxiliary method of classroom teaching process. It can help students quickly and accurately understand the relevant hydraulic components.

(3) The educational software possess strong realistic and is easy to understand.

The three-dimensional teaching software, are made in accordance with the true size of the relevant hydraulic components, so it is extremely realistic. In the course of the experiment, students can quickly and accurately find the hydraulic components in a number of hydraulic components, and easily and quickly complete the relevant experiments.

(4) The educational software possess a variety of simulation enhancements.

The connection of flexible pressure tube and hydraulic components was made two locations to imitate the actual connection. Once due to negligence, the connection between flexible pressure tube and hydraulic components does not reach the second location. After the hydraulic system started, it will suddenly appear blue and give students a deep impression caused serious accidents, It allows students to understand the precautions and to prevent from appearing relating operational risk during the real course of the experiment.

\section{CONCLUSIONS}

The three-dimensional teaching software can be used either as a hydraulic pump performance test prep courses. It can also be used as auxiliary teaching methods of teaching classroom. It can further improve students' learning efficiency and enhance the ability of students to integrate theory with practice.

\section{REFERENCES}

[1] Jiansheng $\mathrm{Hu}$, Li Yang, Zhengjun Wang. Construction of Textbooks and Practiceof Mechanical Drawing Course. Chinese Vocational and Technical Education, 2012, 29:5860.

[2] Wang Wei-dong, Li Hai-qing. Application of Virtual Reality Technology in the Numerical Control Maintenance Software Development and Teaching. Journal of Sichuan University of Science \& Engineering (Natural Science Edition), 2012, 2:31-34.

[3] WANG Fei, XU Xiao-hui. Study and practice on 3D CAD software assisted teaching for Engineering Graphics. Research in Teaching, 2010. 33(3):61-64.

[4] SUN Rong-min; HU Yi-hua; PAN Yu-qian. The Discussion about Mechanical CAD Software Combined with the Mechanical Theory of Teaching. Equipment Manufacturing Technology, 2011, 12:207-209. 